$\xi=-1$

\title{
A Millimeter Wave Antenna using Slots for Defense Applications
}

\author{
Deepa Negi ${ }^{1}$, Rajesh Khanna ${ }^{2}$ \\ ${ }^{1,2}$ ECED, Thapar Institute of Engineering \& Technology (Deemed University), Patiala, Punjab, India \\ *Corresponding author E-mail: negideepa21@gmail.com
}

\begin{abstract}
In this paper, a rectangular dual band millimeter wave (MMW) microstrip antenna using $\mathrm{U}$ and circular slot is designed for defense applications. The antenna operates in the (57-64) GHz unlicensed frequency band. The proposed antenna is designed using RT/duroid substrate having dielectric constant 2.3 , thickness $0.04 \mathrm{~mm}$ and strip line feeding technique. The proposed antenna results are simulated and optimized using Computer Simulation Technology (CST) simulation software. The maximum return loss achieved is $-15 \mathrm{~dB}$ and -25.45 $\mathrm{dB}$ respectively for both $\mathrm{U}$ and circular slot. Simulation results show that the antenna having circular slot gave better results. The antenna simulation results such as return loss, gain and directivity are presented in this paper.
\end{abstract}

Keywords: Millimetre Wave; Stripline Feed; U Slot; Gain; Directivity.

\section{Introduction}

Microstrip patch antennas are widely used now-a-days due to its various features like light weight, low profile, low fabrication cost and conformal nature. Despite many advantages, it suffers from low gain and narrow bandwidth. Therefore, various bandwidth enhancement techniques are used by the researchers to overcome this problem [1]. The most common is the designing of different slots in the antenna. Slots can be seen as resonant LC circuits, which allow the current to follow longer path thus increasing the effective dimensions of the patch. MMW technology is going to be a promising candidate for the next generation communications. MMW band has various advantages like large spectral capacity, interference immune, compact antenna structure and allows large data transfers than any other antenna.

Despite many advantages, it suffers from weak penetration, high path loss and therefore used for short range applications. Designing an antenna at such a high frequency is considered to be a challenging task as higher the frequency smaller will be its size, which further makes it very difficult to fabricate [2]. In the proposed antenna, we have used $57 \mathrm{GHz}$ to $64 \mathrm{GHz}$ of unlicensed frequency band. The proposed antenna resonates at $60 / 77 \mathrm{GHz}$, which makes it a dual band antenna operating in $\mathrm{V}$ and $\mathrm{W}$ band. In the past, slots have been used extensively to enhance the bandwidth of antenna. In [3], a circular microstrip antenna with different slots have been presented. In [4], a rectangular microstrip patch antenna is loaded by triple rectangular slot and dual circular slots. In [5], a slotted rectangular antenna is proposed for hepta band operation with notch-band property. In [6], a new broadband and dual band circular slot cut modified circular microstrip antenna is analyzed and proposed. In [7] a multifunctional antenna is designed using two U slots on the radiating patch. In [8] a wide band antenna with E shaped patch is proposed which covers a wide bandwidth serving various wireless applications. In [9] a modified structure with inverted $\mathrm{E}$ shaped patch is proposed having defected ground structure to achieve bandwidth enhancement. In [10] the proposed an- tenna structure achieved miniaturization by introducing $\mathrm{U}$ slot on the patch.

The rest of the paper is divided into different sections as follows: section 2 presents the antenna design using $\mathrm{U}$ and circular slot. Simulation results of the proposed antenna are discussed in the section 3, finally the conclusion is discussed in section 4 .

\section{Antenna Design}

The proposed antenna has been designed using two different slots i.e. U and circular. The proposed antenna used Duroid as substrate with dielectric constant 2.3 and thickness $0.04 \mathrm{~mm}$. The conducting parts of the antenna used copper (annealed) with thickness $0.01 \mathrm{~mm}$. Both the antennas are fed with $50 \Omega$ transmission line, further both the antennas used rectangular patch as its having highest impedance bandwidth. Figure 1(a) and 1(b) shows the geometry of proposed $\mathrm{U}$ and Circular sot antenna.

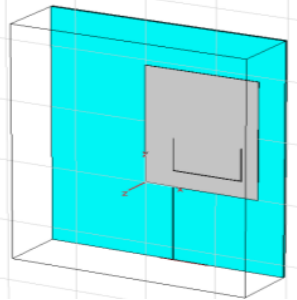

(a)

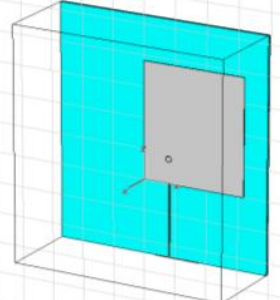

(b)
Fig. 1. Geometry of Proposed Antenna with (a) U Slot (b) Circular Slot

The dimensions of the proposed antenna are calculated by using transmission line model. The various parameters are given by the following equations:

$W=\frac{\mathrm{C}}{2 \mathrm{f}_{0} \sqrt{\left(\varepsilon_{\mathrm{r}}+1\right) / 2}}$

$L=L_{e f f}-2 \Delta L$ 


$$
L_{e f f}=\frac{c}{2 f_{o} \sqrt{\varepsilon_{\text {reff }}}}
$$

where $\mathrm{W}$ and $\mathrm{L}$ are the width and length of the patch. Using the above equations the dimensions of the proposed antenna are calculated and by using the iterative trials the parameters are further optimized.The parameters like feed position ,feed width, slot dimensions and position are optimized to get the desired results. The dimensions of the proposed antenna are: Patch length $=1.59 \mathrm{~mm}$, Patch width $=1.91 \mathrm{~mm}$, Length of stripline $=1.2 \mathrm{~mm}$, Width of stripline $=0.05 \mathrm{~mm}$. For U slot: Slot width $=0.95 \mathrm{~mm}$, Slot length $=0.43 \mathrm{~mm}$ and Slot thickness $=0.007 \mathrm{~mm}$. For circular slot: Radius of outer circle $=0.05 \mathrm{~mm}$, Radius of inner circle $=0.044 \mathrm{~mm}$.

\section{Simulation Results}

In this section, the results like return loss, gain and directivity are simulated and presented using CST microwave studio. Fig. 2 and 3 shows the return loss plots for $U$ and Circular slot. The circular slot return loss $(-25.45 \mathrm{~dB})$ is better than the U slot $(-15 \mathrm{~dB})$.

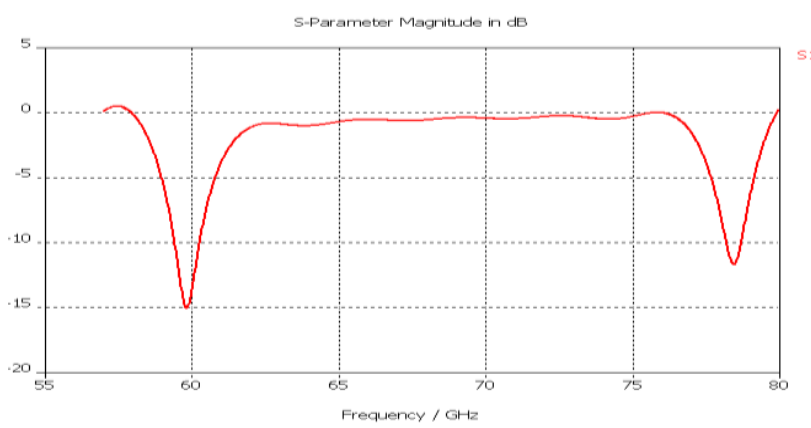

Fig. 2. Return loss curve of proposed antenna with U slot

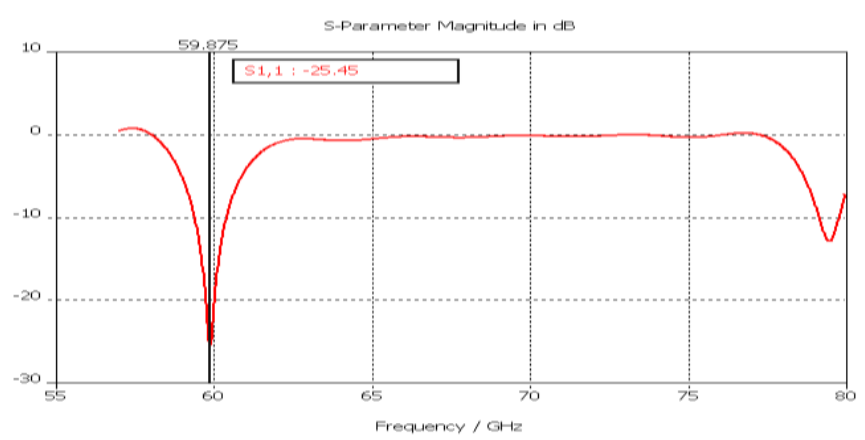

Fig. 3. Return loss curve of proposed antenna with circular slot

The Gain and directivity of the slots are almost similar. Circular slot gain is $5.819 \mathrm{~dB}$ and directivity is $7.842 \mathrm{dBi}$. U slot gain is $5.629 \mathrm{~dB}$ and directivity is $7.772 \mathrm{dBi}$., therefore we have shown results of circular slot only. Figure 4 and 5 shows the directivity and gain of the circular slot antenna.
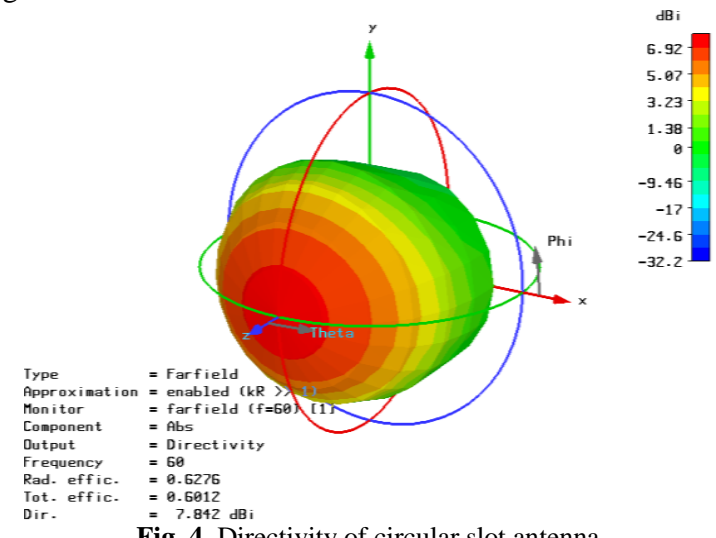

Fig. 4. Directivity of circular slot antenna

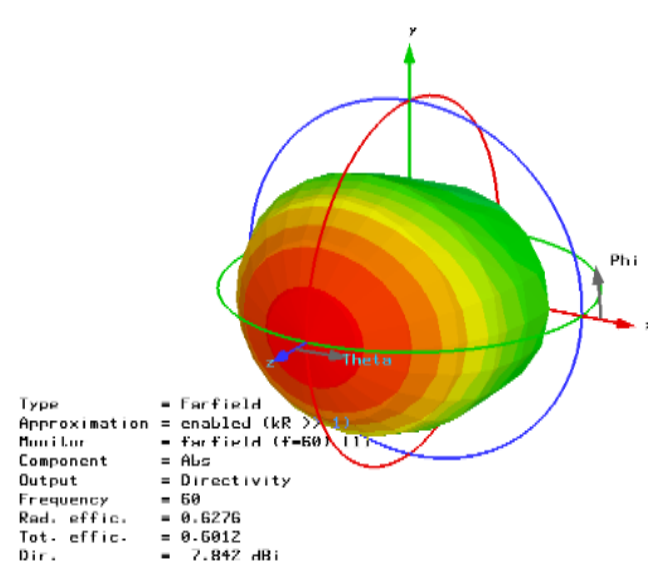

$A B i$
6.92
5.97
3.23
1.38
0
-9.46
-17
-21.6
-32.2

Fig. 5. Gain Plot of circular slot antenna

\section{Conclusion}

In this a dual band, rectangular microstrip patch antenna is designed using $U$ and circular slot for defense applications. The proposed antenna operates over (57-64) GHz unlicensed frequency band. Good results are obtained in terms of reflection coefficient, gain and directivity. The antenna that is designed using the circular slot has given better results in terms of return loss and bandwidth. Moreover, circular slot has only one degree of freedom as compared to U slot, which makes it comparatively easier to design and optimize. In future, the proposed antenna can be used for $5 \mathrm{G}$ or multiple input multiple output (MIMO) applications.

\section{References}

[1] Kin-Lu Wong, "Planar Antennas for Wireless Communication", Published by John Wiley \& Sons, Inc., Chapter: 2, Pages: 26-65, 2003.

[2] Sunakshi Puri, Kiranpreet Kaur, Naveen Kumar, "A Review of Antennas for Wireless Communication Devices", International Journal of Electronics \& Electrical Engineering, vol 2, no. 3, pp. 199-201, September 2014.

[3] Dabas, D., \& Abhishek (2013), Design of Circular Microstrip Patch Antenna with different Slots for WLAN \& Bluetooth Application. International Journal of Engineering Research \& Technology 2, 1662-1669.

[4] Srivastava, R., Ayub, S., Singh, V. K., \& Saini, J. P. (2014, April). Dual band rectangular and circular slot loaded microstrip antenna for WLAN/GPS/WiMax applications. In Fourth International Conference on Communication Systems and Network Technologies (CSNT), pp. 45-48.

[5] Sze, J. Y., \& Wong, K. L.(2003), Slotted Rectangular Microstip Antenna for Bandwidth Enhancement. IEEE Transaction on Antennas and Propagation 48, 1149-1152.

[6] Deshmukh, A. A., Makwana, S., \& Jain, V. (2014). Dual band dual polarized slot cut modified circular microstrip antenna. International Journal of Computer Applications 85, 37-41.

[7] Basavarajappa, V., \& Vinoy, K. J. (2010). An integrated wideband multifunctional antenna using a microstrip patch with two Uslots. Progress In Electromagnetics Research 22, 221-235.

[8] Yang, F., Zhang, X. X., Ye, X., \& Rahmat-Samii, Y. (2001), Wide-band E-shaped patch antennas for wireless communications. IEEE transactions on antennas and propagation 49, 10941100 .

[9] Lin, W. P., Yang, D. H., \& Lin, Z. D. (2014). Compact dual-band planar inverted-e-shaped antenna using defected ground structure. International Journal of Antennas and Propagation 2014.

[10] G. F. Khodaei, J. Nourinia And C. Ghobadi. A Practical Miniaturized U-Slot Patch Antenna With Enhanced Bandwidth. Progress In Electromagnetics Research B 3, 47-62. 